\title{
Comparative Stability Analysis of Silicone Carbide Nanotube using MD Simulation and FEM Software
}

\author{
Kadir Mercan \\ Department of Civil Eng., Mehmet Akif Ersoy University, Burdur, Turkey \\ E-mail address: kmercan@mehmetakif.edu.tr \\ ORCID numbers of authors: \\ 0000-0003-3657-6274
}

Received date: 17.11.2019

Accepted date: 05.12.2019

\begin{abstract}
In this paper, the stability analysis of silicon carbide nanotube (SiCNT) has been investigated. Nanotubes has many advantages with its very high surface area, exceptional electrical conductivity and resistance to high temperature and external loads. Although nanotubes can be obtained without superfluous effort, it is not facile to achieve experimental analyzes due to demand of laboratory equipment with astronomical cost. To obtain critical buckling loads, both molecular dynamic (MD) method and ANSYS finite element software is used in current paper. LAMMPS (Large-scale Atomic/Molecular Massively Parallel Simulator) is used for calculating critical buckling load. Also, VMD (visual molecular dynamics) is used to visualize atoms in molecular dynamic analysis.
\end{abstract}

Keywords: SiCNT, stability, molecular dynamics, finite element.

\section{Introduction}

The popularity of nanotube and nanomaterial research and usage has been dramatically raised with the understanding of its gigantic potential and advantages [1-3]. Nanomaterials such as graphene has attracted worldwide attention due to their superior material properties and almost unlimited usage areas such as aerospace, drug delivery, modern automotive technology, high efficiency computers, textile etc. [4-6]. The superiority of nanomaterials comes from its very high surface area, exceptional electrical conductivity and resistance to high temperature and external loads. Outstanding mechanical stiffness and tensile strength put nanomaterials forward to conventional engineering materials. The discovery of Carbon nanotube (CNT) has been composed as a 
revolutionary point for many areas. After CNT, new types of nanotubes with superior properties have been produced and used. Most used nanotubes in engineering is CNT, SiCNT, and boron nitride nanotube (BNNT).

Improvement in material and usage of nano-sized materials such as graphene, silicone, CNT, SiCNT (silicon carbide nanotube), etc. resulted in smaller and more effective end products. Comparing nanotubes SiCNT is the one with the highest resistance to heat $\left(1000{ }^{\circ} \mathrm{C}\right.$ in air) and BNNT is the one with highest stiffness with Young modulus $1.8 \mathrm{TPa}$ while CNT can resist temperature up to $600{ }^{\circ} \mathrm{C}$ in air and $1.0 \mathrm{TPa}$ Young modulus. These limits guide researchers and engineers to specify which nanotube to use in different usage areas with different requirements. Because of astronomical cost in building a laboratory with sufficient equipment to perform stability analyzes in nano-size, many computational mechanic methods have been used to make analyzes possible with much lower cost [7].

\section{FEM Analysis using ANSYS}

The history of finite element method dates back to 1942. Any material in nature eventuate from multiple atoms coming together in a certain order. For SiCNT, these atoms are silicon and carbon atoms bonding in hexagonal shape with $2.29 \AA$ bond length. Finite element method based on modeling the structure by meshing in smaller parts. Results are more satisfactory with finer meshing. In figure 1 the real structure of SiCNT is demonstrated at left side of figure with the finite element (meshed) model at the right side. Meshing is one of the major problem to obtain accurate results. Inaccurate meshing leads inaccurate results in software. As coarse meshing is an issue in meshing, very fine meshing can also end up with very long calculating and simulating period in software.
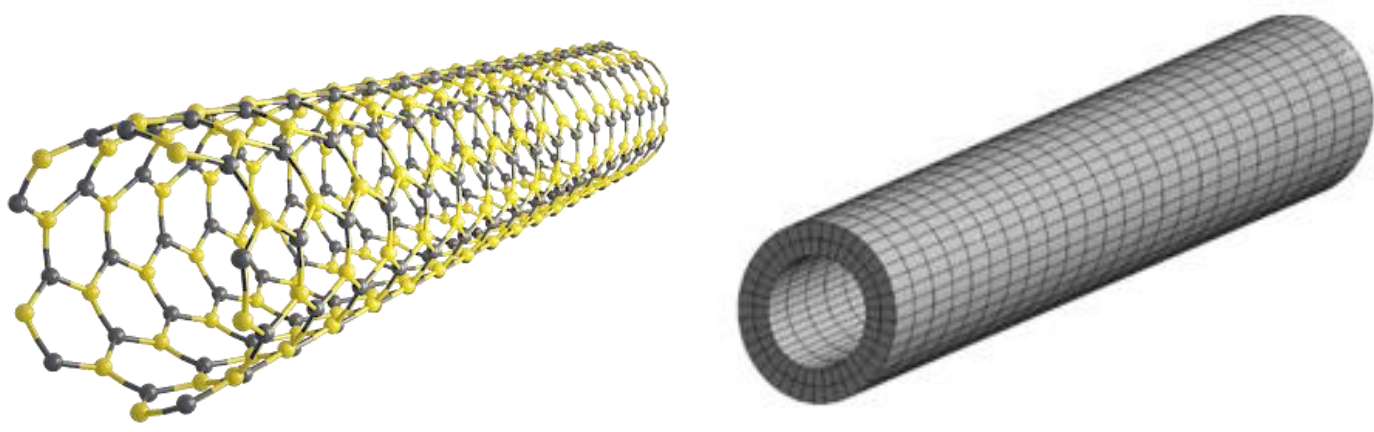

Fig. 1. Real and finite element model of SiCNT 
As it can be seen from figure 1, the finite element model used in ANSYS multiphysics consist of a simple tubular structure. SiCNT material properties was applied to the model to obtain critical buckling load.

\section{MD Simulation using LAMMPS}

Molecular dynamic is an effective and accurate tool to calculate the critical buckling load of nanotubes. LAMMPS open source software is used to perform molecular dynamic simulation. To model interatomic potential function many model has been used such as Tersoff, Tersoff-Brenner, AIREBO (Adaptive Intermolecular Reactive Empirical Bond Order). Models differs from each other in many ways. To illustrate, AIREBO potential is a multi-body force field which is developed for hydrocarbons and includes REBO, Lennard-Jones, torsional potentials as sub-components. Xu et al. [8] have demonstrated that AIREBO is able to predict wrinkling patterns in graphene sheets which can be observed in experimental analyzes [9]. Furthermore, Zheng et al. have demonstrated that AIREBO can also capture the hybridization state caused by the deformation-induced curvature [10].

AIREBO potential can be expressed as follows [11]

$$
E=\frac{1}{2} \sum_{i} \sum_{j \neq i}\left(E_{i j}^{R E B O}+E_{i j}^{L J}+\sum_{k \neq i, j} \sum_{l \neq i, j, k} E_{k i j l}^{T O R S}\right)
$$

where

$$
\begin{gathered}
E_{i j}^{R E B O}=V_{i j}^{R}\left(r_{i, j}\right)+b_{i, j} V_{i j}^{A}\left(r_{i, j}\right) \\
E_{i j}^{L J}=S\left(t_{r}\left(r_{i, j}\right)\right) S\left(t_{b}\left(b_{i, j}^{*}\right)\right) C_{i, j} V_{i j}^{L J}\left(r_{i, j}\right)+\left(1-S\left(t_{r}\left(r_{i, j}\right)\right)\right) C_{i, j} V_{i j}^{L J}\left(r_{i, j}\right) \\
E^{T O R S}=\frac{1}{2} \sum_{i} \sum_{j \neq i} \sum_{k \neq i, j} \sum_{l \neq i, j, k} w_{i, j}\left(r_{i, j}\right) w_{j, k}\left(r_{j, k}\right) w_{k, l}\left(r_{k, l}\right) V^{T O R S}\left(\omega_{i, j, k, l}\right) \\
V^{\text {TORS }}(\omega)=\epsilon\left(\frac{256}{405} \cos ^{10}\left(\frac{\omega}{2}\right)-\frac{1}{10}\right)
\end{gathered}
$$

here $V_{i j}^{R}$ and $V_{i j}^{A}$ are repulsive and attractive pairwise popentials. These potentials can be obtained by atom types and depends on the atomic distance. $S(t)$ is universal switching function. 

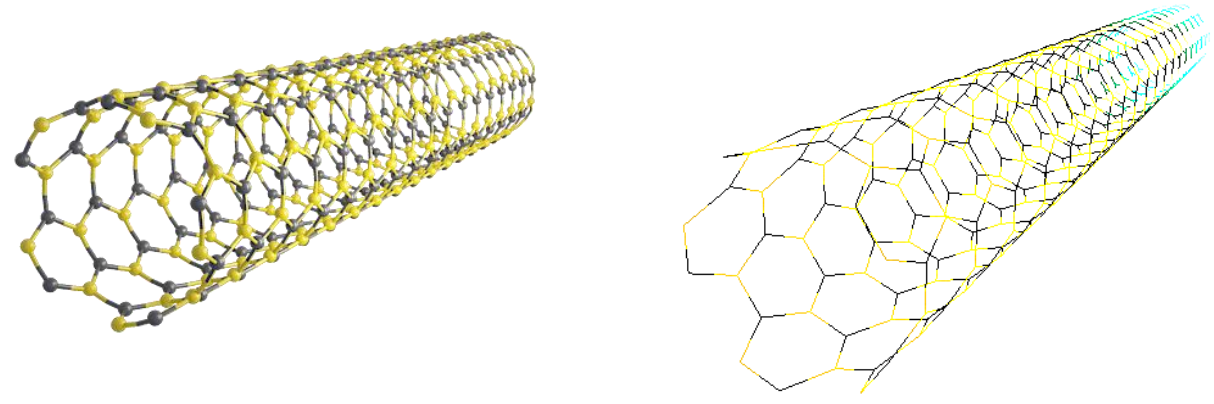

Fig. 1. Real and atomic model of SiCNT

To compare, continuum mechanical models of nanotubes can give accurate results by using size effective theories which take the size effect of nanotubes to improve results by differing the operating equations from classical models and theories $[12,13]$.

\section{Conclusion}

Molecular dynamics simulation method has the advantage of defining every atom of nanotubes and interactions between these atoms. On the other hand, finite element software's are able to model solid or fluid and simulate many scenario leading to perform various analyzes in very short time. Although the speed and ease of finite element software's is attractive, software become insufficient when it comes to model the interaction between atoms. These issue lead to perform analyzes only on perfect (undamaged atoms and interactions) models while the freedom in molecular dynamic is infinite. In experiments which nanotubes are used, it is seen that nanotubes with atomic defects are existing in most experiments caused by limited fabrication technics which means that perfect nanotubes with perfect sequence and bonds is rare in practice. Consequently, although MD simulation has more complications in modeling and performing analyzes compared with finite element softwares, the method has the great advantage of modeling each atoms and bonds separately. This advantage leads to more accurate results.

\section{Reference}

[1] Mercan, K., Civalek, O., Buckling analysis of Silicon carbide nanotubes (SiCNTs) with surface effect and nonlocal elasticity using the method of HDQ. Composites Part B-Engineering, 114, 35-45, 2017.

[2] Akgoz, B., Civalek, O., Effects of thermal and shear deformation on vibration response of functionally graded thick composite microbeams. Composites Part B-Engineering, 129, 77-87, 2017.

[3] Civalek, O., Kiracioglu, O., Free vibration analysis of Timoshenko beams by DSC method. International Journal for Numerical Methods in Biomedical Engineering, 26(12), 1890-1898, 2010. 
[4] Demir, C., Civalek, O., A new nonlocal FEM via Hermitian cubic shape functions for thermal vibration of nano beams surrounded by an elastic matrix. Composite Structures, 168, 872-884, 2017.

[5] Numanoglu, H.M., Akgoz, B., Civalek, O., On dynamic analysis of nanorods. International Journal of Engineering Science, 130, 33-50, 2018.

[6] Demir, C., Civalek, O., On the analysis of microbeams. International Journal of Engineering Science, 121, 14-33, 2017.

[7] Demir, C., Mercan, K., Numanoglu, H.M., Civalek, O., Bending Response of Nanobeams Resting on Elastic Foundation. Journal of Applied and Computational Mechanics, 4(2), 105$114,2018$.

[8] Xu, Z.P., Buehler, M.J., Geometry Controls Conformation of Graphene Sheets: Membranes, Ribbons, and Scrolls. Acs Nano, 4(7), 3869-3876, 2010.

[9] Mehralian, F., Beni, Y.T., Molecular dynamics analysis on axial buckling of functionalized carbon nanotubes in thermal environment. Journal of Molecular Modeling, 23(12), 2017.

[10] Zheng, Y.P., Xu, L.Q., Fan, Z.Y., Wei, N., Lu, Y., Huang, Z.G., Mechanical Properties of Graphene Nanobuds: A Molecular Dynamics Study. Current Nanoscience, 8(1), 89-96, 2012.

[11] Stuart, S.J., Tutein, A.B., Harrison, J.A., A reactive potential for hydrocarbons with intermolecular interactions. Journal of Chemical Physics, 112(14), 6472-6486, 2000.

[12] Demir, Ç., Akgöz, B., Erdinç, M.C., Mercan, K., Civalek, Ö., Elastik bir ortamdaki grafen tabakanın titreşim hesabı. Gazi Üniversitesi Mühendislik-Mimarlık Fakültesi Dergisi, 32(2), 2017.

[13] Emsen, E., Mercan, K., Akgöz, B., Civalek, Ö., Modal analysis of tapered beam-column embedded in Winkler elastic foundation. International Journal of Engineering \& Applied Sciences, 7(1), 1-11, 2015. 